一技術報告一

自動二輪車のエンジンブレーキ性能と交通事故解析への応用

戸田 均 ${ }^{1}$, 小倉崇生 ${ }^{1}$, 伊藤智泰 ${ }^{2}$, 磯和克樹 ${ }^{2}$, 植地弘毅 ${ }^{2}$, 大賀 涼 $^{3}$, 奥野 健 $^{3}$

1三重県警察本部刑事部科学捜査研究所

干514-8514 三重県津市栄町一丁目100番地

2三重県警察本部交通部交通指導課

干514-8514 三重県津市栄町一丁目100番地

3 科学警察研究所

干277-0882 千葉県柏市柏の葉 6 丁目 3 番地 1

\title{
Application of Motorcycle Engine Brake Performance to Traffic Accident Reconstruction
}

\author{
Hitoshi Toda ${ }^{1}$, Takao Ogura ${ }^{1}$, Tomoyasu Ito $^{2}$, Katsuki Isowa ${ }^{2}$, Kouki Ueji ${ }^{2}$, \\ Ryo $\mathrm{Oga}^{3}$ and Ken Okuno ${ }^{3}$
}

${ }^{1}$ Forensic Science Laboratory, Mie Prefectural Police Headquarters

1-100, Sakaemachi, Tsu, Mie 514-8514, Japan

${ }^{2}$ Traffic Enforcement Division, Mie Prefectural Police Headquarters

1-100, Sakaemachi, Tsu, Mie 514-8514, Japan

${ }^{3}$ National Research Institute of Police Science

6-3-1, Kashiwanoha, Kashiwa, Chiba 277-0882, Japan

(Received 24 November 2015; accepted 8 September 2016;

Published online 3 November 2016 in J-STAGE DOI: 10.3408/jafst.711)

The motorcycle has a high running stability. Therefore, the motorcycle can keep running without the rider before and after a traffic accident. For Traffic accident reconstruction which involves an unmanned motorcycle, we needed the deceleration value of the motorcycle during running without a rider. Running without a rider is in much the same state as running with the engine brake on. Therefore, we investigated performance of motorcycle engine brake to use for analysis of traffic accident.

Engine displacement of the motorcycles with manual transmission (MT) we used was from $250 \mathrm{cc}$ to $1200 \mathrm{cc}$. And that with automatic transmission (AT) was 50 $\mathrm{cc}$ and $250 \mathrm{cc}$. We examined coasting tests in various speeds and various gears.

In the result, we found that the motorcycle with MT speed bear a direct proportionate relationship to deceleration of engine brake running. And then, we found

* 本論文の内容は, 日本法科学技術学会第17回学術集会発表 (平成23年11月) に执いて奨励賞を受賞した. 
that speed change per unit distance doesn't depend on the motorcycle speed in case of high speed running. However, speed change per unit distance decreased in the case of low speed running by the motorcycle with MT. Simultaneously, the motorcycle with AT increased the value of speed change.

Key words: Engine Brake, Motorcycle, Coasting Test, Traffic Accident Reconstruction

\section{緒 言}

自動二輪車の交通事故解析のために，バリア衝突 実験や実車衝突実験によるホイールベース変形量お よび被衝突車両の変形量に着目した研究1-5)や，転 倒滑走中の二輪車の減速度に関する研究6-9) が行わ れている.しかし，四輪車と比べると，事故解析に 必要となるデータが不足しており，特に自動二輪車 特有の現象については, 多くの研究が求められてい る.

自動二輪車はジャイロ効果などにより高速での走 行安定性が高く，事故時に運転手が自動二輪車から 離れた状態でも自走する現象がみられる，自動二輪 車が自走している状態では, 転がり抵抗, 空気抵抗 に加え, 動力伝達部の抵抗により車両が減速してい く.この状態はエンジンブレーキにより減速してい る状態と同様であるが，自動二輪車のエンジンブ レーキによる減速度についてはほとんど報告されて いない。また，森下らの研究10) から，自動二輪車の エンジンブレーキによる減速が等減速度ではなく， 走行速度に影響されることが報告されており, 走行 速度が不明な交通事故解析に抢いては, エンジンブ レーキによる減速を検討することが困難である.

そこで本研究では, 排気量の異なる複数の自動二 輪車を用いた惰行試験によりエンジンブレーキの性 能を調査するとともに, 得られたデータの交通事故 解析への応用について検討を行ったので報告する.

なお，本研究に抢けるエンジンブレーキ性能は， 動力伝達部の抵抗のみではなく, 転がり抵抗や空気 抵抗を加えた実走行時の減速性能として定義する。

\section{実験方法}

\section{1. 実験概要}

指定の速度まで自動二輪車を加速させた後に，ア クセルをオフにしてギアを繋いだ状態での惰行試験 を行った，惰行試験では，実験車両を指定の速度ま で加速させる加速区間，惰行を行う直前に速度を調 整する調整区間及び惰行区間を設定し，各区間は安 全性を考慮し運転手が走行時に任意に設定した。惰 行開始位置については，惰行が安定した位置を実験 車両に取り付けた GVS 速度・距離計（株式会社バ イオスシステム製）の計測データから判定した.

解析する惰行区間は $40 \mathrm{~m}$ とし，惰行開始位置か らの距離，惰行区間の高低差及び惰行試験時の速度 変化についても，GVS 速度・距離計を用いた。

\section{2. 実験車両}

実験車両は，手動変速機の車両（以下，MT 車) を5 台（MT1〜MT5：1200 cc, $750 \mathrm{cc}, 400 \mathrm{cc}, 250 \mathrm{cc}$ クラス）抢よび自動変速機の車両（以下， AT 車) を 2 台（AT1, AT2： $250 \mathrm{cc}, 50 \mathrm{cc}$ クラス）の計 7 台である. 各車両の外観を Fig. 1 に，諸元を Table 1 に示す。

\section{3. 実験条件}

走行速度は $30 \sim 120 \mathrm{~km} / \mathrm{h}$ を目標とし，2箇所の 実験場所において以下の条件で行った.

\section{(1) 実験 1}

実験場所：開通前の道路（平均斜度 $1.4 \%$, 乾燥 アスファルト路面）

実験は走行区間を往復することによ り上り傾斜と下り傾斜の両方で行っ た.

走行速度 : $70 \mathrm{~km} / \mathrm{h}$ 以上

実験車両 : MT1 MT3 

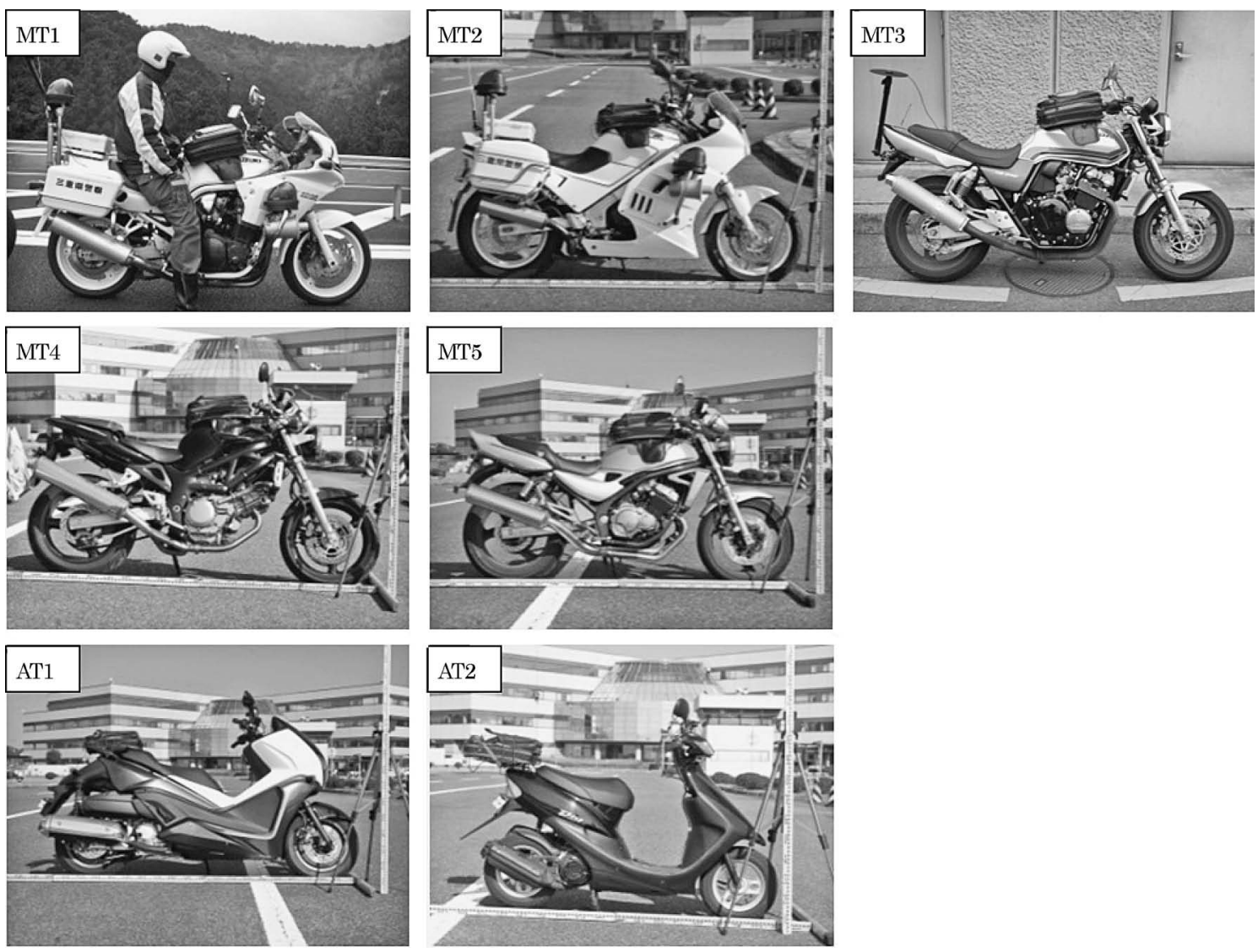

Fig. 1 Motorcycles Used for Test.

Table 1 Dimensions of Motorcycles.

\begin{tabular}{|c|c|c|c|c|c|c|c|c|}
\hline \multicolumn{2}{|l|}{ 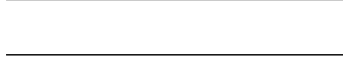 } & MT1 & MT2 & MT3 & MT4 & MT5 & AT1 & AT2 \\
\hline \multicolumn{2}{|l|}{ Engin } & 4 Stroke & 4 Stroke & 4 Stroke & 4 Stroke & 4 Stroke & 4 Stroke & 2 Stroke \\
\hline \multirow{2}{*}{\multicolumn{2}{|c|}{$\begin{array}{l}\text { Displacement }(\mathrm{L}) \\
\text { weight }(\mathrm{kg})\end{array}$}} & 1.156 & 0.748 & 0.399 & 0.399 & 0.249 & 0.248 & 0.049 \\
\hline & & 280 & 260 & 180 & 180 & 151 & 185 & 73 \\
\hline \multicolumn{2}{|c|}{ Front Tire Size } & $120 / 70 \mathrm{R} 17$ & 110/80R 17 & $120 / 60 \mathrm{R} 17$ & $120 / 60 \mathrm{R} 17$ & 110/70R17 & 110/90R13 & 90/90R 10 \\
\hline \multicolumn{2}{|c|}{ Rear Tire Size } & $180 / 55 \mathrm{R} 17$ & 140/80R17 & $160 / 60 \mathrm{R} 17$ & $160 / 60 \mathrm{R} 17$ & 140/70R17 & 140/70R 13 & $90 / 90 \mathrm{R} 10$ \\
\hline \multirow{4}{*}{$\begin{array}{l}\text { Transmission } \\
\text { Gear Ratio }\end{array}$} & 6 th & - & - & 1.130 & 0.851 & 0.892 & - & - \\
\hline & 5 th & 0.833 & 1.083 & 1.240 & 0.961 & 1.000 & - & - \\
\hline & 4 th & 0.956 & 1.227 & (Not Tested) & 1.125 & 1.160 & - & - \\
\hline & $3 \mathrm{rd}$ & (Not Tested) & 1.450 & (Not Tested) & (Not Tested) & (Not Tested) & - & - \\
\hline \multicolumn{2}{|c|}{$\begin{array}{l}\text { Primary Reduction } \\
\text { Gear Ratio }\end{array}$} & 1.565 & 1.939 & 2.171 & 2.620 & 3.291 & 2.444 & 3.153 \\
\hline \multicolumn{2}{|c|}{$\begin{array}{l}\text { Secondary Reduction } \\
\text { Gear Ratio }\end{array}$} & 3.200 & 2.812 & 2.933 & 3.000 & 3.428 & 3.083 & 3.461 \\
\hline
\end{tabular}

実験ギア：最高ギアおよび一段下のギア 実験回数：各ギアにおいて 8〜12回

(2) 実験 2

実験場所：三重県運転免許センター試験コース
（傾斜なし，乾燥アスファルト路面） 走行速度 : $80 \mathrm{~km} / \mathrm{h}$ 以下 実験車両：MT2, MT4, MT5, AT1 およびAT2 実験ギア：MT 車は最高ギア，一段下のギアおよ 

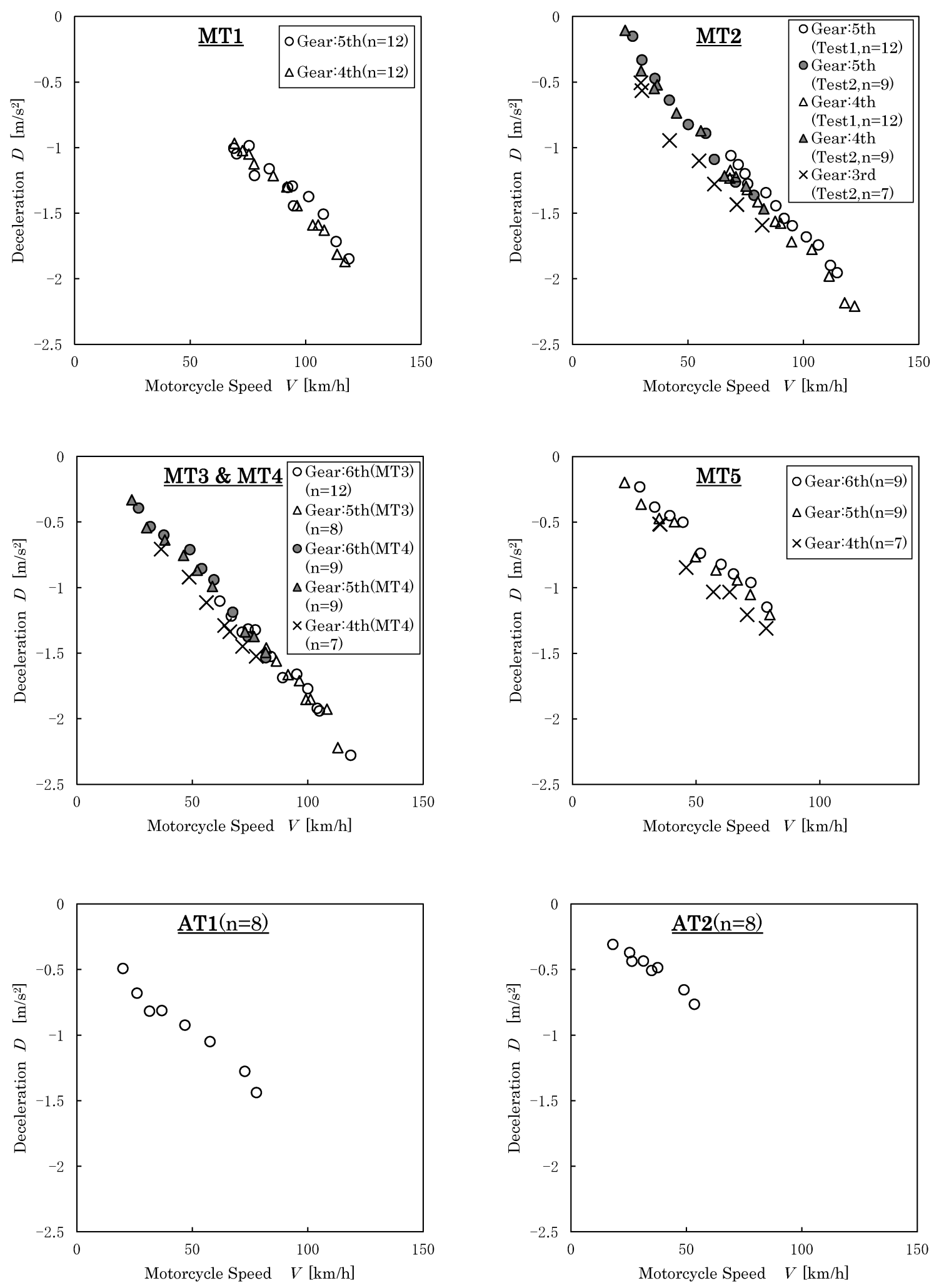

Fig. 2 The Relations Between Deceleration and Motorcycle Speed. 
び二段下のギア．AT 車はドライブギ ア.

実験回数：各ギアにおいて 7〜9 回

なお，いずれの場所での実験においても，実験車 両の運転手（体重 $70 \mathrm{~kg}$ ）は前傾姿勢により可能な 限り空気抵抗の影響を少なくした。

\section{結果および考察 \\ 1. 走行速度と減速度の関係}

各実験車両の走行速度を惰行区間の進入速度と退 出速度の中間值とし, 走行速度 $V(\mathrm{~km} / \mathrm{h})$ と惰行 区間の減速度 $D\left(\mathrm{~m} / \mathrm{s}^{2}\right)$ の関係を Fig. 2 に示す. な拈，Fig. 2 には 1 回の走行に対して 1 つのデータ がプロットしてあり，以下の図についても同様であ る.

実験 1 の結果については傾斜の影響を除くため, 以下の式により補正を行った.

$$
\frac{1}{2} \times M \times v_{0}^{2}-M \times D \times L-M \times \mathrm{g} \times H=\frac{1}{2} \times M \times v_{1}^{2}
$$

より，減速度 $D$ について整理し，

$$
D=\frac{1}{2 \times L} \times\left(v_{0}^{2}-v_{1}^{2}\right)-\frac{\mathrm{g} \times H}{L}
$$

$v_{0}$ は惰行区間進入速度 $(\mathrm{m} / \mathrm{s}), \quad v_{1}$ は惰行区間退出 速度 $(\mathrm{m} / \mathrm{s}), M$ は車両質量 $(\mathrm{kg}), \mathrm{g}$ は重力加速度 $\left(\mathrm{m} / \mathrm{s}^{2}\right), L$ は惰行区間距離 $(\mathrm{m}), H$ は惰行開始点 を基準とした高低差 $((\mathrm{m})$ ，上り勾配が正)である.

全ての車両において走行速度と減速度には強い相 関がみられ，走行速度が高くなるほど減速度が高く （数值の絶対值が大きく）なっている。これは, 走 行中の自動二輪車がアクセルをオフにした場合に駆 動輪の回転によりエンジンを回すこととなり，エン ジンの回転が抵抗となるためである.エンジン回転 時の負荷はエンジン回転数に比例し, MT 車のエン ジン回転数は走行性能線図 ${ }^{11)}$ にも表されるように車 両の走行速度と比例関係にある.このため, アクセ ルをオフにした場合の減速度が車両の走行速度と比 例する.

一方で，走行速度が低い場合に走行速度と減速度 の関係が比例関係から外れ，エンジンブレーキによ る減速の効果が小さくなっている。これは, 走行中
の自動二輪車のアクセルをオフにしてエンジン回転 数が低下しても，アイドリング時の回転数に近づく とエンジンの回転が駆動力として作用するためであ る.

走行速度と減速度が比例関係にある速度について は車両により異なるが，本研究による車両及びギア では, Fig. 2 より $50 \mathrm{~km} / \mathrm{h}$ 以上の走行速度に抢いて 走行速度と減速度が比例関係で表されると考えた. そこで, Fig. 3 に MT 車の走行速度 $50 \mathrm{~km} / \mathrm{h}$ 以上で の走行速度と減速度の関係を同一グラフに示し, Table 2 に各条件での走行速度と減速度についての 近似式を示す.

各条件での近似式で高い相関係数を示しており， 走行速度 $50 \mathrm{~km} / \mathrm{h}$ 以上では走行速度と減速度に比例 関係があると考えられる。そこで，250 cc から1200 $\mathrm{cc}$ までの MT 車に抢ける走行速度 $V(\mathrm{~km} / \mathrm{h})$ と減 速度 $D\left(\mathrm{~m} / \mathrm{s}^{2}\right)$ の関係について, 本研究の測定值 をすべて含む実験式として以下の式を得た.

$$
D=(-0.0131 \sim-0.0207) \times V
$$

\section{2. 交通事故解析への応用}

エンジンブレーキ中の減速度が走行速度によって 大きく変化するため, 長距離を減速中の車両や走行 速度が不明である場合については Fig. 3 および Table 2 のデータを交通事故解析に適用することは困 難である. そこで, 本研究では得られたデータの交 通事故解析への応用について検討した。

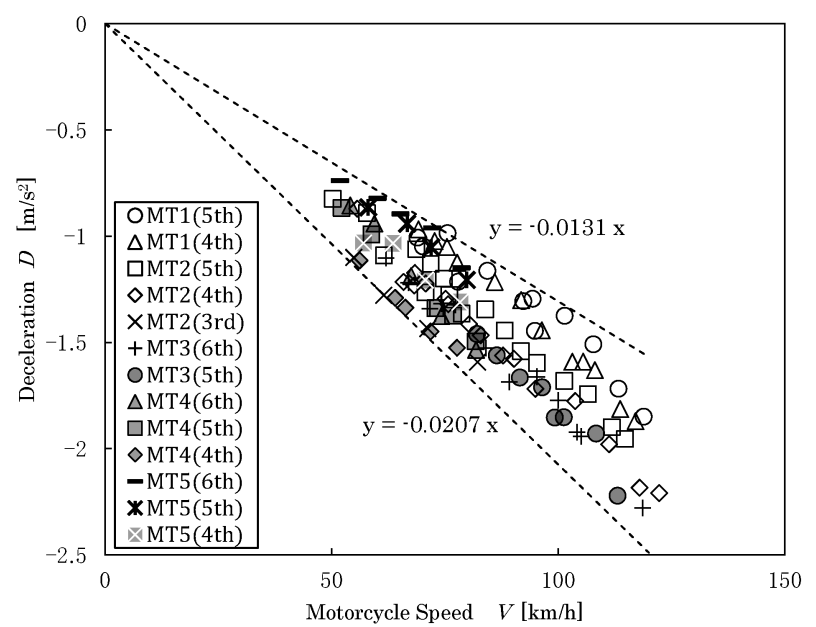

Fig. 3 The Relations Between Deceleration and MT Motorcycle Speed. 
Table 2 Formulate to Estimate the Deceleration $D$ from Motorcycle Speed $V$ over $50 \mathrm{~km} / \mathrm{h}$ (MT Motorcycles).

\begin{tabular}{|c|c|c|c|c|}
\hline \multirow{2}{*}{ Motorcycle } & \multicolumn{4}{|c|}{ Gear } \\
\hline & 6th & 5 th & 4 th & $3 r d$ \\
\hline MT1 & - & $\begin{array}{c}D=-0.0145 V \\
\left(\mathrm{R}^{2}=0.915\right)\end{array}$ & $\begin{array}{c}D=-0.0150 \mathrm{~V} \\
\left(\mathrm{R}^{2}=0.949\right)\end{array}$ & (Not Tested) \\
\hline MT2 & - & $\begin{array}{c}D=-0.0165 V \\
\left(\mathrm{R}^{2}=0.976\right)\end{array}$ & $\begin{array}{c}D=-0.0177 V \\
\left(\mathrm{R}^{2}=0.983\right)\end{array}$ & $\begin{array}{c}D=-0.0200 \mathrm{~V} \\
\left(\mathrm{R}^{2}=0.961\right)\end{array}$ \\
\hline MT3 & $\begin{array}{c}D=-0.0183 \mathrm{~V} \\
\left(\mathrm{R}^{2}=0.972\right)\end{array}$ & $\begin{array}{c}D=-0.0183 V \\
\left(\mathrm{R}^{2}=0.919\right)\end{array}$ & (Not Tested) & (Not Tested) \\
\hline MT4 & $\begin{array}{c}D=-0.0177 V \\
\left(\mathrm{R}^{2}=0.896\right)\end{array}$ & $\begin{array}{c}D=-0.0178 \mathrm{~V} \\
\left(\mathrm{R}^{2}=0.965\right)\end{array}$ & $\begin{array}{c}D=-0.0200 V \\
\left(\mathrm{R}^{2}=0.987\right)\end{array}$ & (Not Tested) \\
\hline MT5 & $\begin{array}{c}D=-0.0139 V \\
\left(\mathrm{R}^{2}=0.944\right)\end{array}$ & $\begin{array}{c}D=-0.0147 V \\
\left(\mathrm{R}^{2}=0.959\right)\end{array}$ & $\begin{array}{c}D=-0.0170 V \\
\left(\mathrm{R}^{2}=0.880\right)\end{array}$ & (Not Tested) \\
\hline
\end{tabular}

式(3)から, 走行速度 $50 \mathrm{~km} / \mathrm{h}$ 以上において速度 と減速度が比例関係へ近似されており, 走行速度 $v(\mathrm{~m} / \mathrm{s})$, 定数 $k$ を用いて以下の式を仮定した.

$$
D=k \times v
$$

ここで, 位置エネルギを考慮しないエネルギ保存則 より，

$$
\frac{1}{2} \times M \times v_{0}{ }^{2}-M \times D \times L=\frac{1}{2} \times M \times v_{1}^{2}
$$

が成り立ち，代表速度を $v=\left(v_{0}+v_{1}\right) / 2$ と定義し， 式(4)および式(5)を用いると，

$$
\frac{v_{0}-v_{1}}{L}=\frac{2}{v_{0}+v_{1}} \times D=k
$$

が導かれる。

式(6)は単位距離を走行した間の速度变化（= $\left(v_{0}\right.$ $\left.\left.-v_{1}\right) / L\right)$ が定数（=k）であることを示している. そこで, 単位距離当たりの速度変化 $\Delta V / \Delta L(\mathrm{~km}$ $\left.\mathrm{h}^{-1} \mathrm{~m}^{-1}\right)$ を定義し, 走行速度との関係について整 理した. その結果を Fig. 4 に, MT 車について同一 グラフにをとめたものを Fig. 5 に示す.なお，傾 斜のない実験 2 にいては走行実験データから $\Delta V$ $/ \Delta L$ を直接算出し, 実験 1 の值については式(2)よ り傾斜の影響を補正した減速度をもとに式(6)によ り算出した. また, 走行速度 $50 \mathrm{~km} / \mathrm{h}$ 以下のデータ についても Fig. 4 及び Fig. 5 に示した.

Fig. 4 から, MT 車は走行速度が $50 \mathrm{~km} / \mathrm{h}$ 以上の 場合には単位距離当たりの速度变化がおおむね定 となることが確認された。つまり, 単位距離当たり の速度变化は速度依存性が低く，エンジンブレーキ により減速した区間が判明すれば，その間での速度
変化が算出可能であると考えられた.

走行速度 $50 \mathrm{~km} / \mathrm{h}$ 以上に抢ける $250 \mathrm{cc}$ から $1200 \mathrm{cc}$ までの MT 車の単位距離当たりの速度変化につい て, 本研究の測定值をすべて含む值の範囲は 0.169 〜 0.269 ( $\left.\mathrm{km} \mathrm{h}^{-1} \mathrm{~m}^{-1}\right)$ であった（Fig. 5). また， 各車両について走行速度 $50 \mathrm{~km} / \mathrm{h}$ 以上に扮ける単位 距離当たりの速度変化の平均值を Table 3 に示す.

一方, 走行速度が $50 \mathrm{~km} / \mathrm{h}$ 以下においては, 単位 距離当たりの速度変化が一定とならないことが確認 された．MT車については，走行速度が低下すると 単位距離当たりの速度変化が小さくなり, AT 車で は単位距離当たりの速度変化が大きくなった.

このため, 本研究のデータを使用する場合にはエ ンジンブレーキがどの程度の速度まで行わ机ていた かに注意し，適用する場合には十分な検討が必要と なる。

\section{結 言}

二輪車のエンジンブレーキ性能を調査するため複 数の車両を用いた惰行試験を行い, 以下の結論を得 た。

（1）エンジンブレーキによる減速度 $D\left(\mathrm{~m} / \mathrm{s}^{2}\right)$ と 走行速度 $V(\mathrm{~km} / \mathrm{h})$ には強い相関があり, MT 車では走行速度 $50 \mathrm{~km} / \mathrm{h}$ 以上に抢いて

$$
D=k \times V
$$

と近似できる. 本研究に打ける排気量 $250 \sim 1200 \mathrm{cc}$ クラスの MT 車では $k=-0.0131 \sim-0.0207$ となった.

（2） MT 車は，走行速度が $50 \mathrm{~km} / \mathrm{h}$ 以上の場合に 

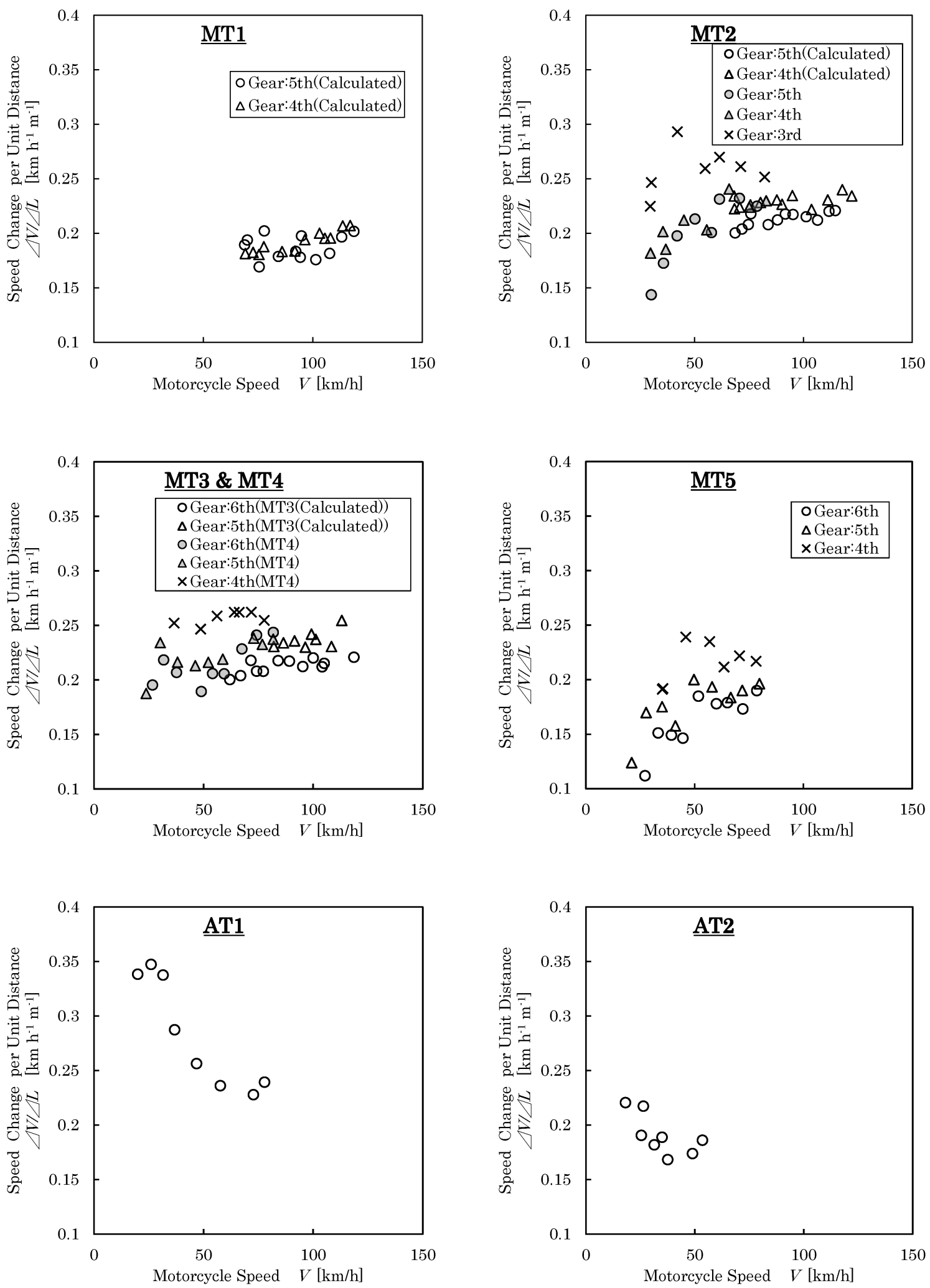

Fig. 4 The Relations Between Speed Change per Unit Distance and Motorcycle Speed. 


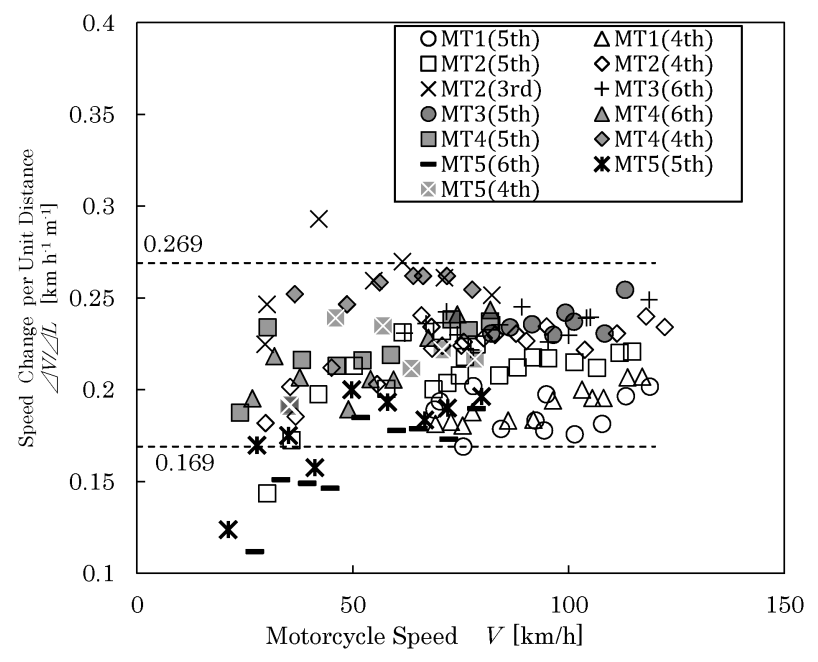

Fig. 5 The Relations Between Speed Change per Unit Distance and MT Motorcycle Speed.

Table 3 Average of Speed Change per Unit Distance over $50 \mathrm{~km} / \mathrm{h}$ (MT Motorcycles).

\begin{tabular}{ccccc}
\hline \multirow{2}{*}{ Motorcycle } & \multicolumn{4}{c}{ Gear } \\
\cline { 2 - 5 } & 6th & 5 th & 4th & 3rd \\
\hline MT1 & - & 0.187 & 0.191 & (Not Tested) \\
MT2 & - & 0.215 & 0.228 & 0.260 \\
MT3 & 0.235 & 0.237 & Not Tested) & (Not Tested) \\
MT4 & 0.225 & 0.229 & 0.260 & (Not Tested) \\
MT5 & 0.181 & 0.191 & 0.221 & (Not Tested) \\
\hline \multicolumn{5}{c}{} \\
& & & $\left(\mathrm{km} \mathrm{h}^{-1} \mathrm{~m}^{-1}\right)$
\end{tabular}

はエンジンブレーキ中の単位距離当たりの速度 変化が打打むね一定となる。

本研究に打ける排気量250～1200 cc クラスの MT 車では，エンジンブレーキ中の単位距離当 たりの速度変化は $0.169 \sim 0.269\left(\mathrm{~km} \mathrm{~h}^{-1} \mathrm{~m}^{-1}\right)$

となった。

（3）走行速度が $50 \mathrm{~km} / \mathrm{h}$ 以下に打けるエンジンブ レーキ中の単位距離当たりの速度変化は, $\mathrm{MT}$ 車では小さくなり AT 車では大きくなった。こ のため，エンジンブレーキによる減速が $50 \mathrm{~km} /$ $\mathrm{h}$ 以下まで行われている場合には，本研究の
データの適用に注意を要する.

\section{参考文献}

1）上山 勝, 斎藤修二, 牧下 寛, 最上和生, 石山昱夫．衝突実験による自動二輪車の破損挙 動と衝突速度の推定. 科学警察研究所報告法科 学編, 41, 56-66, 1988.

2）中谷 有，西本哲也. 二輪車事故の鑑定手法 一二輪車対四輪車の衝突ケース一。自動車研 究, 26, 633-640, 2004.

3）山崎俊一，久保田正美. 二輪車事故の速度解 析. 自動車研究, 27, 155-160, 2005.

4）西本哲也，逸見和生. 実車衝突実験による中 型，小型，原付スクータの速度鑑定方法の提

案. 自動車研究, 24, 161-164, 2002.

5）小出健次, 児玉智章, 中島 浩, 颯田義康. 転倒滑走する二輪車と四輪車の衝突実験. 日本 法科学技術学会誌，12, 159-165, 2007.

6) Warner C. Y., Smith G. C., James M. B., and Germane G. J., Friction Applications in Accident Reconstruction. SAE Technical Paper, No.830612, 1983.

7) Day T. D. and Smith J. R., Friction Factors for Motorcycle Sliding on Various Surfaces. $S A E$ Technical Paper, No.840250, 1984.

8) Lambourn R. F., The Calculation of Motorcycle Speeds from Sliding Distances. SAE Technical Paper, No.910125, 1991.

9) Medwell C. J., McCarthy J. R. and Shanahan M. T., Motorcycle Slide to Stop Tests. SAE Technical Paper, No.970963, 1997.

10）森下順治, 寺辻英治. 交通事故解析に必要々 なる自動二輪車の車両性能 一発進性能および 減速性能について一. 日本交通科学協議会誌, 3, 83-86, 2003.

11）社団法人自動車技術会編. 新編 自動車工学 便覧，pp. 17-25，図書出版社，東京， 1984. 